Article

\title{
Production of Antagonistic Compounds by Bacillus sp. with Antifungal Activity against Heritage Contaminating Fungi
}

\author{
Mara Silva ${ }^{1}$, Tânia Rosado $^{1}$, Marina Gonzalez-Pérez ${ }^{1}$, Débora Gobbo ${ }^{1}$, Dora Teixeira ${ }^{1,2}$ (D), \\ António Candeias ${ }^{1,2}$ and Ana Teresa Caldeira ${ }^{1,2, *}$ \\ 1 HERCULES Laboratory, Évora University, Largo Marquês de Marialva 8, 7000-809 Évora, Portugal; \\ marasilva50@hotmail.com (M.S.); tania.s.rosado@gmail.com (T.R.); marinagonpe@gmail.com (M.G.-P.); \\ debora.gobbo@studio.unibo.it (D.G.);dmt@uevora.pt (D.T.); candeias@uevora.pt (A.C.) \\ 2 Chemistry Department, School of Sciences and Technology, Évora University, Rua Romão Ramalho 59, \\ 7000-671 Évora, Portugal \\ * Correspondence: atc@uevora.pt; Tel.: +351-266-740-800
}

Received: 15 February 2018; Accepted: 21 March 2018; Published: 28 March 2018

\begin{abstract}
In recent years, the population has become acutely aware of the need to conserve the world's resources. The study of new compounds produced by natural means is important in the search for alternative green solutions that act against biodeteriogenic fungi, which promote biodeterioration of built cultural heritage sites. The present paper reports new solutions, derived from Bacillus sp. CCLBH 1053 cultures, to produce lipopeptides (LPP) that can act as green biocides to promote the safeguarding of stone artwork. In the stationary phases of bacteria growth, peptone supplementation and sub-lethal heat activation improve the second cycle of sporulation, greatly enhancing LPP production. The bioactive compounds produced by Bacillus cultures suppress biodeteriogenic fungi growth on stone materials, and, hence, provide an important contribution to the development of new biocides for cultural heritage rehabilitation.
\end{abstract}

Keywords: culture heritage; biodegradation/biodeterioration; Bacillus sp.; bioactive compounds; sporulation; marble materials simulation; biocides

\section{Introduction}

One of the practical approaches for the conservation of biodegraded artwork, including ones made from stone materials, focuses on biocide treatments. Their application aims to prevent and/or control microbial growth [1]. Antimicrobial treatment of stone is frequently of limited benefit because microorganisms regrow rapidly, colonizing from the air or from the interior of the stone [2]. In fact, limestone and marble can deteriorate due to different causes and microbial agents play an important role in this process. Surface appearance and integrity, which are altered by microbial proliferation [2], contribute significantly to the overall deterioration phenomena observed on stone building materials $[3,4]$. Fungal strains, due to their hyphae which are capable of penetrating beneath the stone surface, promote several alterations through the production of organic acids. These include the shrinking and swelling of hyphae and polysaccharides, which provide access for water that can freeze and thaw [2,5].

Biocides based on chemical toxic compounds have been used to mitigate this problem. However, in the past decade, many of the most effective biocides have been banned due to their environmental and health hazards [6-8].

In recent years, the interest in using Bacillus sp. strains as biocontrol agents has increased considerably, as they produce a wide variety of antimicrobial substances [9-13]. LPP produced by 
some Bacillus strains—including surfactin, fengycin, and iturin—are particularly relevant as antifungal agents. Their production seems to be correlated with a starvation process that naturally occurs in Bacillus species [14]. Knowledge of the factors that trigger the production of antifungal LPP compounds by Bacillus strains is vital in the search for alternative biological means to act against biodeteriogenic fungi, which promote biodeterioration of built culture heritage. Sporulation of some Bacillus species, a natural phenomenon that occurs followed by a starvation period, has been previously associated with the production of LPP in liquid cultures [15]. While the mechanisms involved are not yet well established, it has been pointed out that it may be due to the fact that some genes of the sporulating killing factor operon seem to present great similarity to genes involved in the regulation of peptide antibiotics biosynthesis and the signaling of the sporulation gene product Spo0A $[16,17]$. Additionally, sporulation and biosynthesis of peptide antibiotics seem to be activated in response to the same stimuli.

The purpose of this work was to develop and study, in a cultural heritage context, novel green biocides produce by a biotechnological approach using the Bacillus sp. CCLBH 1053 strain. The Bacillus physiological response to nutrient starvation and new supplementation, was also studied in order to understand and clarify the association between bioactive compound production and the Bacillus physiological behavior.

\section{Materials and Methods}

\subsection{Microorganism and Culture Media}

Bacillus sp. CCLBH 1053 (Genbank accession number AY785774), with antifungal potential, as demonstrated in previous studies $[6,18]$ was isolated from healthy Quercus suber in the south of Portugal and identified according morphological, physiological, and biochemical characteristics, and by $16 \mathrm{~S}$ rDNA sequence analysis. The Bacillus cultures were maintained on NA (Nutrient Agar, HIMEDIA, Einhausen, Germany) slants and stored at $4{ }^{\circ} \mathrm{C}$. Cells were suspended in physiological serum and used to inoculate $100 \mathrm{~mL}$ of NB (Nutrient Broth, HIMEDIA, Einhausen, Germany).

\subsection{Bioactive Compound Production Study}

\subsubsection{Bacillus Growth Monitoring}

To monitor Bacillus sp. CCLBH 1053 cell growth, liquid cultures of NB media were incubated for $720 \mathrm{~h}$ at $30^{\circ} \mathrm{C}$ in an orbital shaker at $120 \mathrm{rpm}$ (IKA KS 4000 I control, IKA, Staufen, Germany) and the absorbance was periodically monitored at $600 \mathrm{~nm}$.

The kinetics of the bacterial population growth was modelled using the Gompertz model expressed by $\log N / N_{0}=A \cdot \exp (-\exp (-b-c x))$, where the $N$ is the decimal logarithm of microbial counts $(\log 10(\mathrm{CFU} / \mathrm{mL}))$ at time $\mathrm{t} ; N_{0}$ is the asymptotic log count as time decreases indefinitely $(\log 10(\mathrm{CFU} / \mathrm{mL})) ; A$ is the number of $\log$ cycles of growth $(\log 10(\mathrm{CFU} / \mathrm{mL})) ; b$ is the relative growth rate $\left(\mathrm{h}^{-1}\right)$ and $c$ is the time required to reach the maximum growth rate $(\mathrm{h})$ [19].

The specific growth rate of the microorganism, $\mu(\log 10(\mathrm{CFU} / \mathrm{mL}) / \mathrm{h})$, was determined from experimental data in the exponential phase using the relation $\mu\left(\mathrm{h}^{-1}\right)=(c A) / e$, where $e$ is the Neper number. The time of generation $(g)$ was calculated by $g(h)=\operatorname{Ln} 2 / \mu$ [20]. This equation was fit to triplicate sets of growth data using the non-linear regression modules of the software SigmaPlot (Version 12.0.0, Erkrath, Germany).

\subsubsection{Spore Germination Assay}

In order to understand the physiological response to nutrient starvation and new supplementation of Bacillus sp. CCLBH 1053, and its association with biologically-active compound production, a spore germination study was performed. Three set of assays were conducted in parallel. The NB assays operated as a control, using NB medium for culture growth. 
To induce germination of spores, at $72 \mathrm{~h}$ of culture growth $(100 \mathrm{~mL}$ of NB medium inoculated with Bacillus sp. CCLBH 1053 cells, incubated at $30{ }^{\circ} \mathrm{C}$ and under continuous shaking at $120 \mathrm{rpm}$ ) the cells were: (i) supplemented with previously sterilized peptone ( $8 \%$ of culture volume, $w / v$ ) and incubated again under the same conditions (nutrient broth peptone supplementation assay or NBPS); or (ii) supplemented with peptone and followed by a sub-lethal heat shock of $77^{\circ} \mathrm{C}$ for $12 \mathrm{~min}$ to activate the spores (nutrient broth peptone supplementation and heat-activation assay, NBPSHA).

Powdered peptone (HIMEDIA, Einhausen, Germany) was weighed and transferred into sterilized and dried fresh Erlenmeyer flasks. The dry nutrient preparation was sterilized in an autoclave at $120{ }^{\circ} \mathrm{C}$ for $20 \mathrm{~min}$. The sterilization efficiency was confirmed by dissolving the powdered peptone in $100 \mathrm{~mL}$ and spreading an aliquot of the medium on an NA plate. No colony appeared after $24 \mathrm{~h}$. The assay was performed in triplicate.

The spore concentrations of the initial samples were obtained by counting the number of CFU incorporated on the NA plates. LC-ESI-MS analysis was performed in order to obtain a relative quantification of the bioactive compounds in the different assays. This analysis was performed using a LCQ Advantage ThermoFinnigan mass spectrometer (Thermo Fisher Scientific, Waltham, MA, USA) equipped with an electrospray ionization (ESI) source and an ion trap mass analyzer, as described in [21].

\subsection{Antifungal Inhibitory Capacity Assessment}

\subsubsection{Antifungal Paper Disk Diffusion Assay}

Three biodeteriogenic fungi strains isolated from biodegraded mural paintings-Penicillium glandicola CCLBH-MP101, Aspergillus brasiliensis CCLBH-MP201, and Fusarium buharicum CCLBH-MP301-were used to study the antifungal potential of the produced biocompounds. The fungal strains were identified by $18 \mathrm{~S}$ rDNA sequence analysis with new generation sequencing (NGS) using the MiSeq System, Illumina ${ }^{\circledR}$ (EUA, San Diego, CA, USA) with Nano Kit V2.

Fungal spore suspension was prepared by adding a loopful of hyphae and spores from a malt extract agar (MEA) slant incubated at $25^{\circ} \mathrm{C}$ for 7 days, in $5 \mathrm{~mL}$ of $\mathrm{NaCl} 0.85 \%$ solution. The suspension was filtered by sterilized cotton or triple gauze. A $10^{6} \mathrm{CFU} / \mathrm{mL}$ spore suspension was obtained through dilutions and fungal suspensions were incorporated in MEA at $45^{\circ} \mathrm{C}$ in Petri dishes. Filter paper discs (Macherey-Nagel 827 ATD, Macherey-Nagel, Düren, Germany) were impregnated with $40 \mu \mathrm{L}$ of the Bacillus culture broth. After the cells were removed, the discs were placed on the agar and the Petri dishes were incubated at $25^{\circ} \mathrm{C}$ for $24-48 \mathrm{~h}$.

Commercial antifungal compounds nystatin $(1 \mathrm{mg} / \mathrm{mL})$ were also used as a positive control. The antifungal activity was indicated by the formation of inhibition halos around the discs [22] and their diameter was considered as a measure of sensitivity. The assays were performed in triplicate and the values presented as mean \pm standard deviation.

\subsubsection{In Vitro Assay with Marble Slabs}

To evaluate the real-life efficiency and influence of the new compounds on the activity of biodeteriogenic microorganisms in uncolored marble samples, an assay using the bioactive molecules produced by Bacillus sp. CCLBH 1053 under in situ controlled conditions was performed.

After sterilization, marble slabs of $2 \mathrm{~cm} \times 2 \mathrm{~cm}$ were inoculated with a mixture composed of $1 \mathrm{~mL}$ of Penicillium glandicola CCLBH-MP101 (MP), $10^{5} \mathrm{CFU} / \mathrm{mL}$ spore suspension, $500 \mu \mathrm{L}$ of malt extract, and $500 \mu \mathrm{L}$ of Bacillus sp. CCLBH 1053 liquid culture supernatant, which contained the bioactive compounds produced.

The slabs were incubated at $27^{\circ} \mathrm{C}$, monitored periodically and documented using a digital camera. Control assays were also performed in the absence of the fungal suspension (MCP), in order to test the possible interference of the biocompounds in the structure of the marble slabs.

After one month of incubation all the slabs were air-dried, coated with gold, and examined by scanning electron microscopy (SEM) using a Hitachi S-3700N (Hitachi, Tokyo, Japan) variable 
pressure scanning electron microscope. The microscope was coupled to a Bruker XFlash 5010 energy dispersive X-ray (EDX) spectrometer (Bruker, Berlin, Germany), allowing visualization of the surface "biofilm" and analysis of the elemental composition (point analysis and two-dimensional mapping). The accelerating voltage was $18-20 \mathrm{kV}$.

\subsubsection{DNA Analysis}

Genomic DNA from the slabs in test was extracted using E.Z.N.A. ${ }^{\circledR}$ Stool DNA Kit (VWR-Omega Bio-Tek, Norcross, GA, USA) according to the manufacturer's instructions. Extracted DNA was quantified with the QuantiFluorKit ${ }^{\circledR}$ One dsDNA System (Promega, Madison, WI, USA) by Quantus ${ }^{\mathrm{TM}}$ Fluorometer (Promega, Madison, WI, USA) and used as a biomarker to express microbial development after subtracting the DNA amount present in the MCP control slabs.

\section{Results and Discussion}

\subsection{Biocompound Production Study}

The association between the antibiotic production and Bacillus sporulation is not fully understood. Some authors have suggested that antifungal activity and sporulation are linked phenomena [23,24]. However, some studies on mutant strains described that sporulation increased when antibiotic production decreased [25].

\subsubsection{Cell Growth Dynamics of Bacillus sp. CCLBH 1053}

In order to access the dynamics of Bacillus sp. CCLBH 1053 growth in the NB culture media, the culture development was monitored in time, as shown in Figure 1.

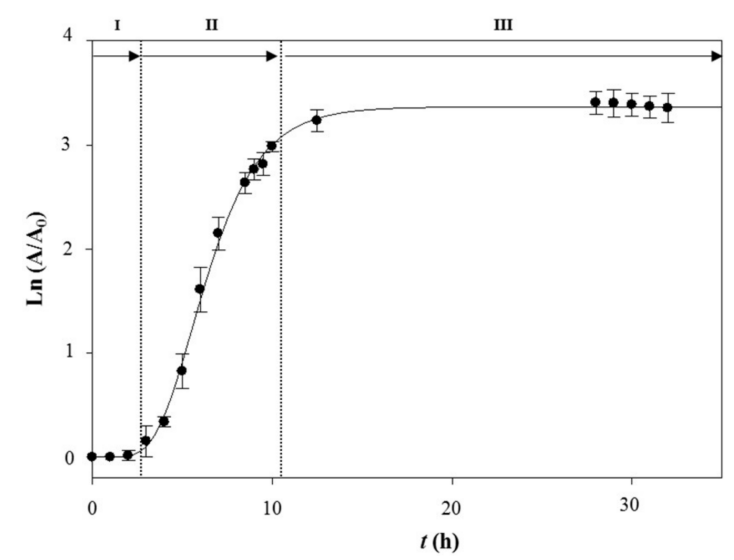

Figure 1. Time course profile of Bacillus sp. CCLBH 1053 in NB medium. All data were determined in triplicate. I-Lag phase; II-Log phase; III-Stationary phase.

The time course profile of Bacillus sp. CCLBH 1053 in NB medium shows a lag phase of about $2 \mathrm{~h}$, a period of exponential growth of approximately $8-10 \mathrm{~h}$, and a stationary phase after $11 \mathrm{~h}$ of culture.

The specific growth rate $(\mu)$ and the generation time $(g)$ were determined from the exponential growth period to be $\mu=0.603 \pm 0.056 \mathrm{~h}^{-1}$ and $g=1.149 \pm 0.095 \mathrm{~h}$, respectively.

\subsubsection{Spore Germination Assessment}

In order to clarify the possible relation between Bacillus sp. CCLBH 1053 sporulation and the antifungal compound production, spore germination assays were performed after $72 \mathrm{~h}$ of growth, either by a nutrient supplementation with fresh peptone (NBPS assay) or a peptone supplementation with an additional heat-activation step (NBPSHA assay). The evolution profile of spores relative to the NB, NBPS, and NBPSHA assays are shown in Figure 2. 


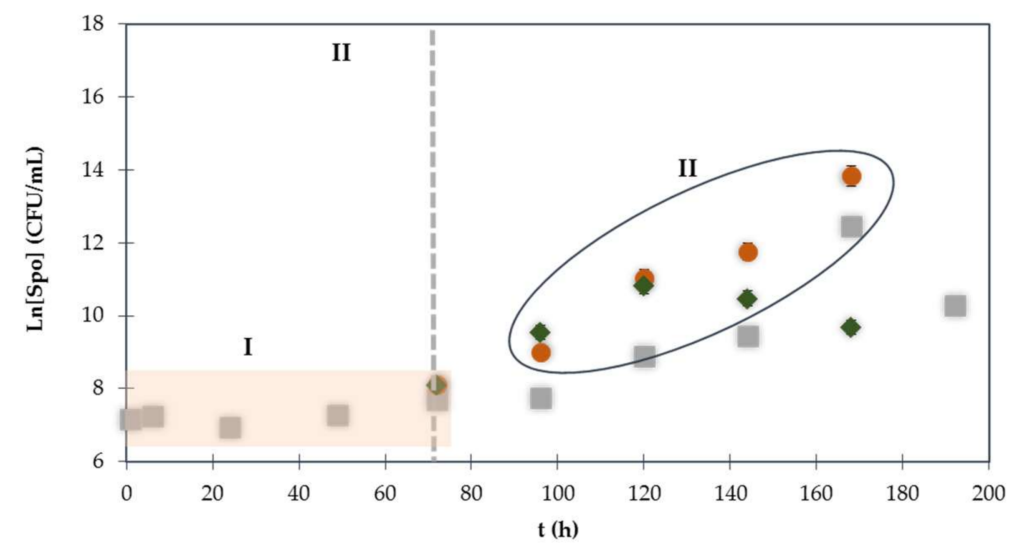

Figure 2. Time course profile of Bacillus spore formation, before and after the peptone supplementation and heat activation assays. ( $₫$ ) Normal growth in NB culture medium; $(\bullet)$ NBPSHA assay; $(\bullet)$ NBPS assay. I-Spore concentration baseline, II-Time with high spore concentration alteration.

In this profile, it is possible to observe two different sporulation behaviors. The first one (Figure 2 (I)) corresponds to the first $72 \mathrm{~h}$ of culture. When the peptone supplementation was performed, and the cells were incubated (stationary phase), the production of spores maintained a constant level. The second behavior occurs after $24 \mathrm{~h}$ of culture and peptone feeding (NBPS and NBPSHA assay). During this time, the spores initiated a gradual progress up to $120 \mathrm{~h}$ of culture, activin $3.08 \times 10^{9} \mathrm{CFU} / \mathrm{mL}$ or up to $240 \mathrm{~h}$ of culture relative to NBPSHA assay with $1.77 \times 10^{14} \mathrm{CFU} / \mathrm{mL}$ (Figure 2 (II)). The thermal shock (NBPSHA assay) seems, in this way, to have a significant effect on spore germination. Rahman et al. (2006) revealed that a supplementation with fresh peptone and a heat-activation of an old culture medium led to an induced spore germination and another round of production of the lipopeptide antibiotic iturin A [14]. The present study confirms that peptone supplementation induces spore germination, supporting and complementing the previous reported study. These results confirm the advantages of performing a peptone supplementation and sub-lethal heat activation in stationary-phase cultures to overcome a second cycle of sporulation. The influence of NBPS or NBPSHA on the production of bioactive compounds associated with a new cycle of sporulation could represent good alternatives to enhance lipopeptide production.

Additionally, the relative quantification of bioactive compounds produce by Bacillus sp. CCLBH 1053 was performed by LC-ESI-MS. The productivity of lipopeptides with $m / z$ 1031, 1045, 1067, 1476 and 1463, corresponding to iturin and fengycin lipopeptides, was determined on days 7 and 12 of incubation for the NBPS and NBPSHA assays (Figure 3).

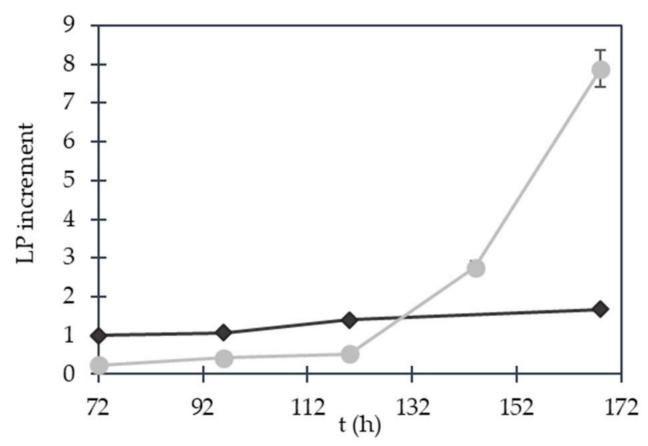

Figure 3. Lipopeptide production increment for the NBPS and NBPSHA assays. The relative percentage of increase was calculated by considering $100 \%$ of the area of the peak corresponding to $0 \mathrm{~h}$ of incubation time after treatment. $(-\bullet)$ NBPSHA; $(\neg-)$ NBPS assay. 
In the NBPS assay, LPP productivity increased 1.6 times higher, and in the NBPSHA assay the heat shocking promoted a productivity increment of 8 times higher relative to normal growth in NB medium. In fact, the activation by nitrogen supplementation and a sub-lethal heat shock generated a significant metabolic activation effect which was also reported in previous studies [14,18].

\subsection{Antimicrobial Effect in Cultural Heritge Assets}

\subsubsection{Antifungal Inhibitory Capacity Assessment}

The antifungal activity of the biocompounds produce by Bacillus sp. CCLBH 1053 cultures in the stationary-phase of bacterial growth were tested against Penicillium glandicola CCLBH-MP101, Aspergillus brasiliensis CCLBH-MP201, and Fusarium buharicum CCLBH-MP301 biodeteriogenic fungal strains isolated from biodegraded mural paintings. Figure 4 show results of the inhibition halos formed, demonstrating the antifungal potential of the produced lipopeptides. All of the biodeteriogenic fungi tested exhibit a higher inhibition level.

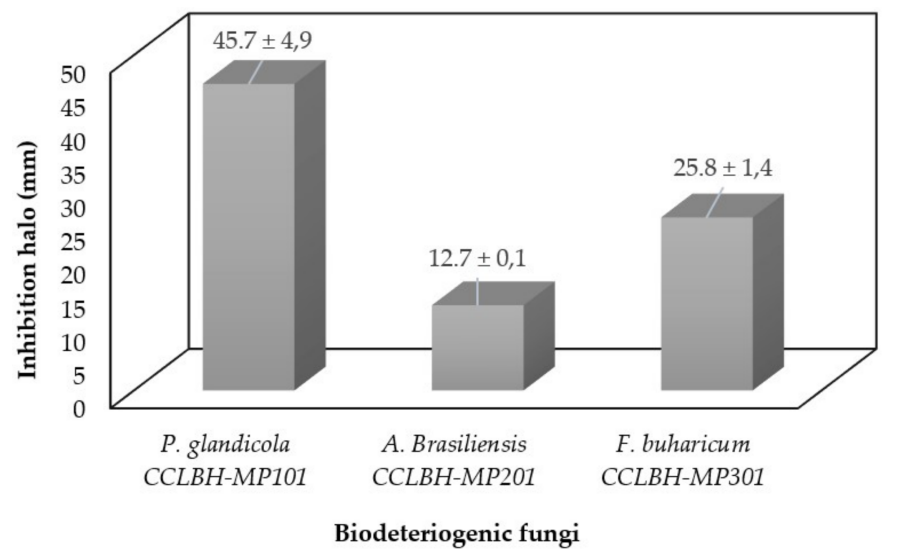

Figure 4. Antifungal activity of the bioactive compounds produced by Bacillus sp. CCLBH 1053 against P. glandicola CCLBH-MP101, A. brasiliensis CCLBH-MP201, and F. buharicum CCLBH-MP301.

The level of inhibition depends strongly on the biodeteriogenic fungal strain tested, with a particular potent effect against P. glandicola CCLBH-MP101.

\subsubsection{Simulation Assays in Marble Materials}

In order to develop and study the real efficiency and influence of the compounds on the biodeteriogenic fungi development, an assay using marble slabs was performed. The slabs were inoculated with P. glandicola CCLBH-MP101 and treated with the produced bioactive compounds under in situ-controlled conditions. Figure 5 shows the macroscopic features corresponding to the marble slab assays at $0,6,15$, and 30 days in the presence of P. glandicola CCLBH-MP101, a common fungi genus found in biodegraded artworks.

After six days of marble slab treatment, the positive control (MCP) begin to exhibit alteration on the slab surface, marking the start of fungal proliferation (Figure 5). At the end of the assay, and after 30 days of incubation, the MCP slabs show evident contamination signals. On the contrary, the MP slabs, with the biocompound treatment, showed few indications of microbiological contamination on the surface; a marked difference compared to slabs without antifungal treatment (MCP).

To confirm the natural compounds' efficiency in the contaminated marble, SEM-EDX analysis (Figure 6) was performed at the end of the assay under variable pressure (40 Pa) without coating.

The MCP slabs (Figure 6a) exhibited a clear presence of microbial cells thriving in the stone. It was possible to observe spores and hyphae penetrating the microstructure of the marble, promoting the proliferation of these microorganisms. Additionally, the EDX elemental analysis showed the presence 
of chemical elements, such as carbon and oxygen, confirming the presence of organic matter in the slabs (Figure 6c).

On the other hand, in the biocompound-treated MP slabs, little evidence of fungal growth was observed by SEM (Figure 6b). The lack of fungal proliferation was confirmed by EDX analysis which only showed the presence of elements in marble's nature composition: Sodium $(\mathrm{Na})$, chlorine $(\mathrm{Cl})$, and calcium (Ca) (Figure 6d). These assays exhibit the great potential of the bacterial bioactive compounds to inhibit fungal proliferation in marble materials.

\begin{tabular}{|c|c|c|c|c|}
\hline Marble stabs & 0 & 6 & 15 & 30 \\
\hline MCP & & $\dot{t}$ & it & : \\
\hline MP & & & & \\
\hline
\end{tabular}

Figure 5. Antifungal activity of the bioactive compounds produced by Bacillus sp. CCLBH 1053 and commercial antifungal drugs against biodeteriogenic fungi isolated from deteriorated mural paintings.

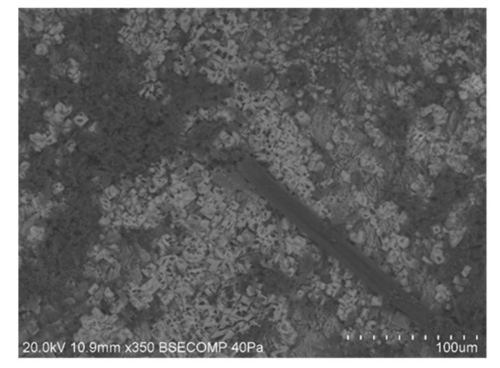

(a)

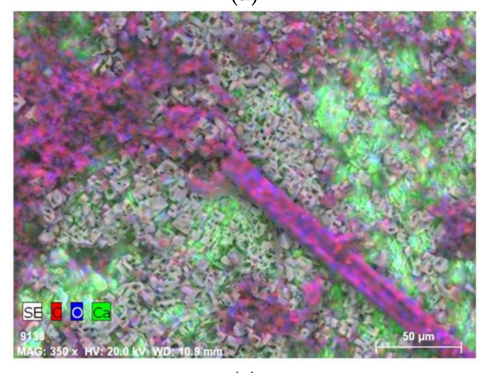

(c)

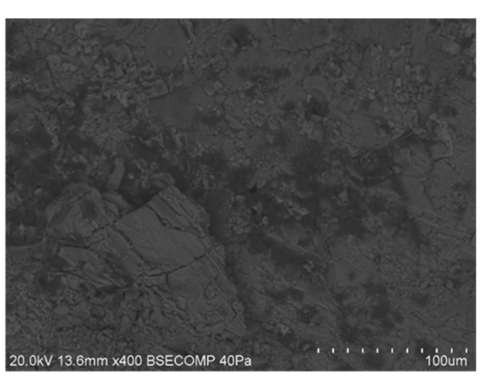

(b)

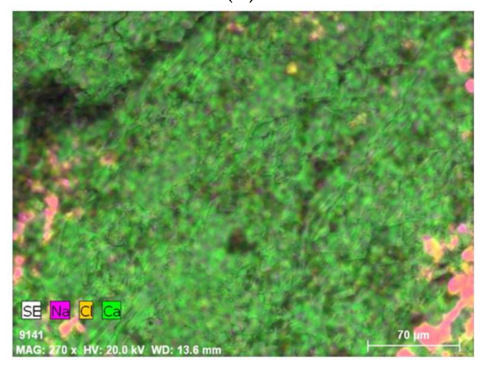

(d)

Figure 6. SEM micrographs of fragments of MCP and MP marble slabs $(\mathbf{a}, \mathbf{b})$ and EDX analysis on the same fragments $(\mathbf{c}, \mathbf{d})$. (a,c) MCP slabs inoculated with P. glandicola CCLBH-MP101. (b,d) MP slabs treated with the biocompounds produced by Bacillus sp. CCLBH 1053.

\subsubsection{Marble Slab DNA}

Thirty days after biocompound application, genomic DNA was extracted directly from the marble in order to access the impact on the development of fungi in the slabs. Figure 7 show the difference, in terms of DNA quantity, between the treated (MP) and untreated (MCP) slabs. 


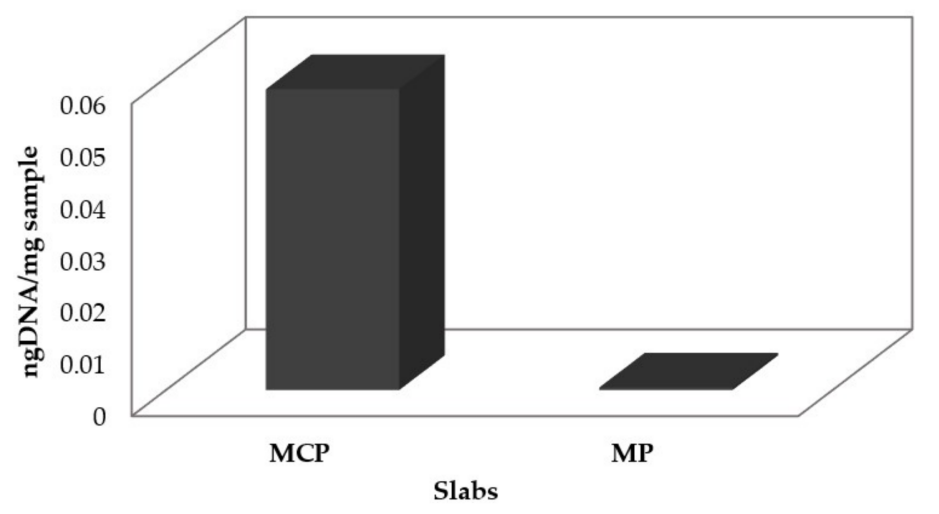

Figure 7. DNA quantification of marble slabs from the simulation assays and the percentage of fungi growth.

The DNA amount in the MP slabs was significant lower than the MCP slabs, showing an inhibition percentage of almost $100 \%$. This provides further evidence for the potential of the bioactive compounds to inhibit fungal growth in marble materials even in the presence of $10^{8}$ fungal spores $/ \mathrm{cm}^{2}$, nutrient broth supplementation, and fungal growth optimal temperature incubation. In this way, the antifungal compounds tested in this work seem to be a potent alternative to mitigate fungi proliferation and consequently the physicochemical mechanisms that promote long-term deterioration in artwork with a marble base construction.

\section{Conclusions}

Understanding the physiological response of Bacillus to nutrient starvation and nutrient supplementation constitutes the first step for improving the production of Bacillus antifungal compounds. In this vein, this work showed that a nutrient supplementation with peptone and a heat activation can be applied to increase bioactive compound production in the latest growth phases of Bacillus sp. CCLBH 1053. The simulation assay using marble slabs allowed the confirmation of the biocompound's fungi inhibition. These results were further confirmed by SEM-EDX analysis and DNA quantification. Therefore, bacterial compound treatment applied to contaminated stone samples provides an important contribution to the development of new mitigation approaches for cultural heritage safeguards and paves the way for the development of an environmentally-friendly novel biocide.

Acknowledgments: The authors gratefully acknowledge the funding source to project "MEDUSA-Microrganisms Monitoring and Mitigation-Developing and Unlocking Novel Sustainable Approaches" ref. ALT20-03-0145FEDER-000015, co-financed by the European Union through the European Regional Development Fund ALENTEJO 2020 (Regional Operational Programme of the Alentejo).

Author Contributions: Mara Silva and Tânia Rosado performed the experimental work; Mara Silva analyzed the results and wrote the manuscript; Marina Gonzalez-Pérez participated on the spore germination assessment experiments; Débora Gobbo participated on the antifungal assays; Dora Teixeira performed the LC-MS analysis. António Candeias participated in writing and the interpretation of the results; Ana Teresa Caldeira performed the isolation, selection, and characterization of lipopeptides producing microorganisms, designed the experiments, and participated in writing and the interpretation of the results.

Conflicts of Interest: The authors declare no conflict of interest.

\section{References}

1. Urzì, C.; De Leo, F. Evaluation of the efficiency of water-repellent and biocide compounds against microbial colonization of mortars. Int. Biodeterior. Biodegrad. 2007, 60, 25-34. [CrossRef]

2. McNamara, C.J.; Mitchell, R. Microbial deterioration of historic stone. Front. Ecol. Environ. 2005, 3, 445-451. [CrossRef] 
3. Sterflinger, K.; Piñar, G. Microbial deterioration of cultural heritage and works of art-Tilting at windmills? Appl. Microbiol. Biotechnol. 2013, 97, 9637-9646. [CrossRef] [PubMed]

4. Scheerer, S.; Ortega-Morales, O.; Gaylarde, C. Microbial deterioration of stone monuments-An updated overview. Adv. Appl. MIicrobiol. 2009, 66, 97-139.

5. Rosado, T.; Gil, M.; Mirão, J.; Candeias, A.; Caldeira, A.T. Oxalate biofilm formation in mural paintings due to microorganisms-A comprehensive study. Int. Biodeterior. Biodegrad. 2013, 85, 1-7. [CrossRef]

6. Silva, M.; Rosado, T.; Teixeira, D.; Candeias, A.; Caldeira, A.T. Production of green biocides for cultural heritage. Novel biotechnological solutions. Int. J. Conserv. Sci. 2015, 6, 519-530.

7. Hegstad, K.; Langsrud, S.; Lunestad, B.T.; Scheie, A.A.; Sunde, M.; Yazdankhah, S.P. Does the wide use of quaternary ammonium compounds enhance the selection and spread of antimicrobial resistance and thus threaten our health? Microb. Drug Resist. 2010, 16, 91-104. [CrossRef] [PubMed]

8. Buffet-Bataillon, S.; Tattevin, P.; Bonnaure-Mallet, M.; Jolivet-Gougeon, A. Emergence of resistance to antibacterial agents: The role of quaternary ammonium compounds-A critical review. Int. J. Antimicrob. Agents 2012, 39, 381-389. [CrossRef] [PubMed]

9. Caldeira, A.T.; Feio, S.S.; Santos Arteiro, J.M.; Roseiro, J.C. Bacillus amyloliquefaciens CCMI 1051 in vitro activity against wood contaminant fungi. Ann. Microbiol. 2007, 57, 29-33. [CrossRef]

10. Ongena, M.; Jacques, P. Bacillus lipopeptides: Versatile weapons for plant disease biocontrol. Trends Microbiol. 2008, 16, 115-125. [CrossRef] [PubMed]

11. Pereira, J.F.; Gudiña, E.J.; Costa, R.; Vitorino, R.; Teixeira, J.A.; Coutinho, J.A.; Rodrigues, L.R. Optimization and characterization of biosurfactant production by Bacillus subtilis isolates towards microbial enhanced oil recovery applications. Fuel 2013, 111, 259-268. [CrossRef]

12. Raaijmakers, J.M.; De Bruijn, I.; Nybroe, O.; Ongena, M. Natural functions of lipopeptides from Bacillus and Pseudomonas: More than surfactants and antibiotics. FEMS Microbiol. Rev. 2010, 34, 1037-1062. [CrossRef] [PubMed]

13. Ruangwong, O.-U.; Chang, C.-I.; Lamine, S.A.; Liang, W.-J. Identification of antifungal compound produced by Bacillus subtilis LB5 with ability to control anthracnose disease caused by Colletotrichum gloeosporioides. Afr. J. Microbiol. Res. 2012, 6, 3732-3738. [CrossRef]

14. Rahman, M.S.; Ano, T.; Shoda, M. Second stage production of iturin A by induced germination of Bacillus subtilis RB14. J. Biotechnol. 2006, 125, 513-515. [CrossRef] [PubMed]

15. Engelberg-Kulka, H.; Hazan, R. Cannibals defy starvation and avoid sporulation. Science 2003, 301, 467-468. [CrossRef] [PubMed]

16. González-Pastor, J.E.; Hobbs, E.C.; Losick, R. Cannibalism by sporulating bacteria. Science 2003, 301, 510-513. [CrossRef] [PubMed]

17. Piggot, P.J.; Hilbert, D.W. Sporulation of Bacillus subtilis. Curr. Opin. Microbiol. 2004, 7, 579-586. [CrossRef] [PubMed]

18. Caldeira, A.T.; Feio, S.S.; Arteiro, J.M.; Coelho, A.V.; Roseiro, J.C. Environmental dynamics of Bacillus amyloliquefaciens CCMI 1051 antifungal activity under different nitrogen patterns. J. Appl. Microbiol. 2008, 104, 808-816. [CrossRef] [PubMed]

19. Chowdhury, B.R.; Chakraborty, R.; Chaudhuri, U.R. Validity of modified Gompertz and Logistic models in predicting cell growth of Pediococcus acidilactici $\mathrm{H}$ during the production of bacteriocin pediocin $\mathrm{AcH}$. J. Food Eng. 2007, 80, 1171-1175. [CrossRef]

20. Zwietering, M.; Jongenburger, I.; Rombouts, F.; Van't Riet, K. Modeling of the bacterial growth curve. Appl. Environ. Microbiol. 1990, 56, 1875-1881. [PubMed]

21. Silva, M.; Pereira, A.; Teixeira, D.; Candeias, A.; Caldeira, A.T. Combined use of NMR, LC-ESI-MS and antifungal tests for rapid detection of bioactive lipopeptides produced by Bacillus. Adv. Microbiol. 2016, 6, 788-796. [CrossRef]

22. Caldeira, A.T.; Santos Arteiro, J.M.; Coelho, A.V.; Roseiro, J.C. Combined use of LC-ESI-MS and antifungal tests for rapid identification of bioactive lipopeptides produced by Bacillus amyloliquefaciens CCMI 1051. Process. Biochem. 2011, 46, 1738-1746. [CrossRef]

23. Dieckmann, R.; Pavela-Vrancic, M.; von Döhren, H. Synthesis of (di) adenosine polyphosphates by non-ribosomal peptide synthetases (NRPS). Biochim. Biophys. Acta (BBA) Protein Struct. Mol. Enzymol. 2001, 1546, 234-241. [CrossRef] 
24. Yazgan, A.; Özcengiz, G.; Özcengiz, E.; Kılınç, K.; Marahiel, M.; Alaeddinoğlu, N.G. Bacilysin biosynthesis by a partially-purified enzyme fraction from Bacillus subtilis. Enzym. Microb. Technol. 2001, 29, 400-406. [CrossRef]

25. Chevanet, C.; Besson, F.; Michel, G. Effect of various growth conditions on spore formation and bacillomycin L production in Bacillus subtilis. Can. J. Microbiol. 1986, 32, 254-258. [CrossRef] [PubMed] 